PontIFícIA UNIVERSIDADE CATÓLICA dO RIO DE JANEIRO

Recuperação de empresas e autogestão como alternativa para a crise brasileira

RodRIGo de RESENDE GonçALVES

Trabalho de Conclusão de Curso

Centro de CIÊnCIAS SOCIAIS - CCS

DePARTAMENTO de AdMINISTRAÇÃo

Graduação em Administração de Empresas 
Rodrigo de Resende Gonçalves

\section{Recuperação de empresas e autogestão como alternativa para a crise brasileira}

Trabalho de Conclusão de Curso

Trabalho de Conclusão de Curso, apresentado ao programa de graduação em Administração da PUC-Rio como requisito parcial para a obtenção do titulo de graduação em Administração.

Orientador : Marcelo Piñeiro

Rio de Janeiro, Dezembro de 2017. 
As cabeças levantadas

Máquinas paradas

Dia de pescar

Pois que toca o trem pra rente

Também de repente

Pode o trem parar

Chico Buarque 


\section{Agradecimentos}

Agradeço a meu pai, Gerson, a minha mãe, Penha e a minha irmã, Mariah, pelo amor incondicional.

A meus amigos Lucas, Felipe e Fernanda, pelo companheirismo.

A minha avó Rosangela pela hospitalidade.

A meu primo Douglas pelo incentivo.

E ao Geraldo pela generosidade. 


\section{Resumo}

Gonçalves, Rodrigo de Resende. Recuperação de empresas e autogestão como alternativa para a crise brasileira. Rio de Janeiro, 2017. Trabalho de Conclusão de Curso - Departamento de Administração. Pontifícia Universidade Católica do Rio de Janeiro.

A recuperação de empresas foi uma alternativa encontrada por milhares de trabalhadores para conseguir manter seus postos de trabalho. Estas organizações são majoritariamente autogeridas e oriundas de um momento de fragilidade econômica. O objetivo deste artigo é, portanto, entender, através de experiências brasileiras e internacionais de recuperação de empresas, a viabilidade de implementar essas práticas com o intuito de amenizar os efeitos causados pelo momento de vulnerabilidade econômica encontrado pelo Brasil.

Palavras-chave: Autogestão. Empresas Recuperadas por Trabalhadores. Crise brasileira.

\section{Abstract}

Gonçalves, Rodrigo de Resende. Recovery companies and self managment as an alternative to the brazilian crisis. Rio de Janeiro, 2017. Trabalho de Conclusão de Curso - Departamento de Administração. Pontifícia Universidade Católica do Rio de Janeiro.

The recovered companies were an alternative found by thousands of workers to keep their jobs. These organizations are mostly self-managed and come from a time of economic fragility. The aim of this article is therefore to understand through Brazilian and international experiences of recovery companies the feasibility of implementing these practices with the intention of mitigating the effects caused by the moment of economic vulnerability found in Brazil.

Key words: Self Management. Worker-Recovered Companies. Brazilian crisis. 


\section{Sumário}

1. Introdução 1

2. Situação atual do Brasil 4

3. A experiência brasileira 8

4 . Experiências históricas em ERTs e autogestão 21

5. Conclusões 26

$\begin{array}{lr}\text { Referências Bibliográficas } & 29\end{array}$

\section{Lista de Figuras}

Figura 1 Critérios para definição de uma empresa recuperada por trabalhadores.

Figura 2 Critérios para definição de uma empresa autogerida......................... 11

Figura 3 Listagem das ERTs brasileiras..................................................... 15

Figura 4 Organograma genérico de uma ERT............................................ 17

\section{Lista de Tabelas}

Tabela 1 Diferenças salariais do cargos de maior e menor remuneração. 18 


\section{Lista de Gráficos}

Gráfico 1 Evolução da taxa de desemprego ao longo dos anos de acordo com o

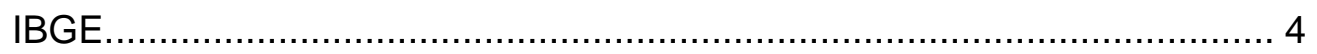

Gráfico 2 Principais fontes de apoio das ERTs brasileiras.............................. 14

Gráfico 3 Mudanças percebidas pelos trabalhadores das ERTs....................... 19 


\section{Introdução}

O curso de Administração aborda diferentes maneiras de gerir uma empresa. Com o intuito de melhorar o desempenho econômico e o bem-estar dos trabalhadores, são escolhidos meios de gestão que consigam ajustar os interesses dos sócios com os dos empregados. Existem muitas práticas de gestão dentro do meio acadêmico que fomentam a igualdade, a autonomia e o bem-estar dos funcionários. Uma delas, a autogestão, é um dos objetos de estudo deste artigo.

O Brasil enfrenta uma grande crise econômica, e as consequências dela são muitas. De acordo com um estudo divulgado pela Boa Vista SCPC - Serviço Central de Proteção ao Crédito, o número de pedidos de falência no país cresceu 12,2\% em 2016 e 16,4\% em 2015. O fechamento dessas empresas acarreta no aumento do número de desempregados, que, de acordo com dados divulgados pelo IBGE em agosto de 2017, ultrapassa $12,6 \%$ da população brasileira, cerca de 13,1 milhões de pessoas. O que fazer diante desse cenário? Existe algum modelo de gestão ou alguma prática de âmbito profissional que possa amenizar esse quadro?

Crises fazem parte da história de um país e existem possíveis saídas encontradas para elas. Serão apresentados alguns exemplos históricos de propostas feitas por trabalhadores em uma tentativa de atenuar os efeitos oriundos de uma crise econômica que resultaram em uma alteração no modelo de produção.

$\mathrm{Na}$ virada do século XX, a Argentina passou por uma crise econômica intensa. Esse colapso gerou um aumento no índice de desemprego, que no ano 2001 chegou a $21,5 \%$ da População Economicamente Ativa (PEA) (Hopstein, 2007:76). Porém, para manter seus postos de trabalho, argentinos adotaram a iniciativa de recuperar as empresas falidas e abandonadas e dar continuidade à produção. Segundo Ruggeri (2014:23), foram recuperadas 235 empresas até o ano de 2013, salvando o emprego de mais de 13.500 trabalhadores. "A recuperação trata-se de uma saída para a economia do país, além de promover a manutenção de postos de trabalhos que seriam perdidos" (Ruggeri, 2014:17). Essa recuperação ocorre quando os trabalhadores da organização que está em falência dão continuidade ao negócio e assumem o controle desta após o abandono por seus executivos.

Dados levantados pela equipe do Programa Facultad Abierta revelam que $60 \%$ das Empresas Recuperadas por Trabalhadores (ERTs) argentinas surgiram entre os anos de 2001 e 2004 (Henriques, 2014:143), período em que a crise estava mais forte no país. Isso 
indica uma relação direta entre o número de empresas recuperadas com o de empresas fechadas.

Ao mencionarmos as ERTs é imprescindível falarmos sobre autogestão, visto que, com a ausência dos sócios, o poder na empresa é descentralizado e todas as decisões são tomadas de maneira coletiva entre os trabalhadores. De acordo com Varanda (2009:81 apud Bottomore, 1988:23), entende-se como autogestão "uma forma democrática de gestão de toda a economia, com base na propriedade social e/ou coletiva dos meios de produção, assim como é uma referência para mecanismos de participação igualitária na tomada de decisão". Com a ausência dos sócios, torna-se necessário repensar toda a estrutura hierárquica. Ao assumirem o poder da empresa, os funcionários tornam-se, portanto, os donos do negócio, e a autogestão foi a maneira de gerir encontrada pela maioria das empresas que foram recuperadas.

Pesquisadores de dez universidades brasileiras - Unicamp, UFRJ, USP, Ufop, Cefet, UFJVM, UFSC, UFPB, UFRN e Unesp - juntamente com o Sistema Nacional de Informações em Economia Solidária (Sies), a Associação Nacional dos Trabalhadores em Empresas de Autogestão e Participação Acionária (Anteag) e a Central de Cooperativas e Empreendimentos Solidários (Unisol), uniram esforços para conhecer a totalidade dos casos de ERTs no país. Existem no Brasil 67 ERTs que se encontram ativas e com competitividade no mercado, com 11.704 funcionários. Essas são empresas que não conseguiram se manter competitivas e foram abandonadas por seus executivos. Com isso, no intuito de manter seus cargos de trabalho, os funcionários continuaram gerindo a organização sob novos moldes e novos desafios.

Evidentemente, esses quase 12 mil funcionários das empresas recuperadas isoladamente não conseguem representar uma esperança à crise que o país enfrenta. Mas entendendo melhor o funcionamento dessas organizações é possível aprender a viabilidade de fomentar esse tipo de prática para que a economia continue girando com essas organizações que se recusam a fechar.

O objetivo deste trabalho é, portanto, entender, através das experiências de recuperação de empresas e de autogestão ocorridas no Brasil e no mundo, os possíveis efeitos positivos que essas práticas podem ter para uma melhoria no momento crítico enfrentado pelo Brasil.

No desenvolvimento deste artigo será feita uma contextualização sobre a situação econômica em que o Brasil está inserido, com o intuito de ressaltar e entender a criticidade atualmente enfrentada. Será apresentada a experiência histórica que o Brasil possui em autogestão e recuperação de empresas, junto com um embasamento teórico desses dois conceitos. Para que a essência dos temas aqui analisados seja compreendida de maneira mais holística, será exposto um panorama sobre como esse assunto é debatido internacionalmente e como essas práticas estão inseridas em outros países. Por fim, haverá 
uma conclusão sobre a efetividade que a autogestão e a recuperação de empresas possuem como alternativa viável ao momento crítico brasileiro. 


\section{Situação atual do Brasil}

O Brasil enfrenta atualmente um momento de fragilidade econômica. Alguns dados podem ajudar a contextualizar o delicado momento em que o país se encontra e, consequentemente, a necessidade de uma reflexão sobre alternativas para diminuir os impactos causados aos brasileiros.

De acordo com dados levantados pelo IBGE, o PIB do país enfrentou oito trimestres seguidos de queda ao longo dos anos de 2015 e 2016, tendo encolhido 3,6\% e 3,8\% nesses dois anos. A queda é causada por diversos fatores relacionados à produção, o que pode ser percebido, por exemplo, através do número de pedidos de falência no país. O Boa Vista SCPC - Serviço Central de Proteção ao Crédito afirma que os casos de falência no Brasil cresceram 12,2\% em 2016 e 16,4\% em 2015. As consequências do fechamento dessas empresas podem ser drásticas, pois resultam no desemprego de milhões de brasileiros que perdem sua principal fonte de renda.

Como apresentado anteriormente na introdução, é este o cenário propício para que ocorra a recuperação de empresas por trabalhadores. Veremos posteriormente exemplos ocorridos no país e no mundo de ERTs que surgiram como solução para dar continuidade à operação dessas organizações que não conseguiram se manter produtivas.

No último trimestre de 2014, o índice de desemprego no Brasil de acordo com o IBGE era de $6,6 \%$ da população. $O$ instituto também afirma que esse percentual sobe para $12,6 \%$ da população em agosto de 2017. São mais de 13 milhões de brasileiros que procuram emprego. O Gráfico 2.1 demonstra a variação ocorrida trimestralmente no índice ao longo dos últimos anos de acordo com dados fornecidos pelo IBGE.

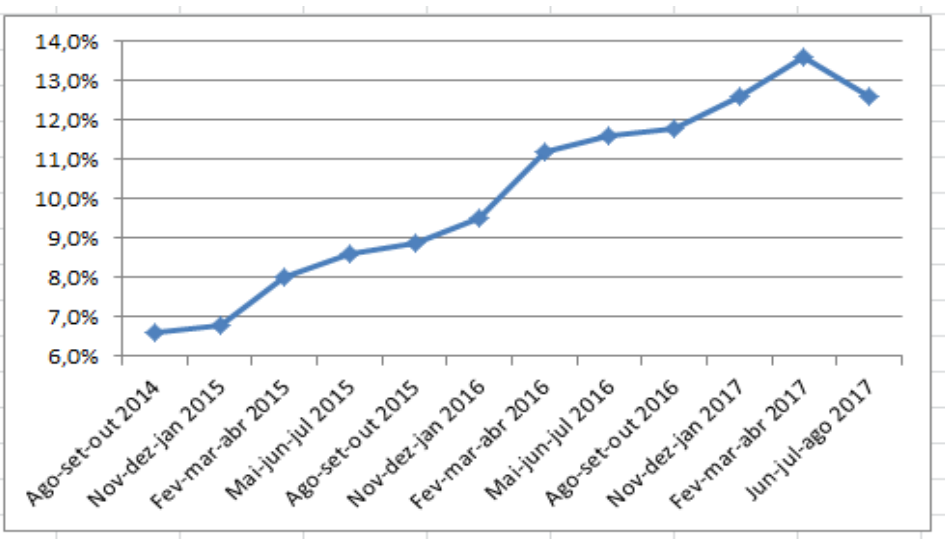

Gráfico 1 Evolução da taxa de desemprego ao longo dos anos de acordo com o IBGE.

Fonte: Elaborado pelo autor. 
O Gráfico evidencia o aumento do percentual de desempregados ocorrido ao longo dos anos. Na segunda metade de 2017 houve uma pequena redução na taxa de desemprego, porém essa breve recuperação não inviabiliza que seja necessária uma preocupação com esses dados, pois não existir a certeza de que essa queda se manterá.

Sem empregos e, consequentemente, com a população enfrentando dificuldades financeiras, a pobreza no país aumenta. O Centro de Políticas Sociais da Fundação Getúlio Vargas revelou que o número de brasileiros abaixo da linha da pobreza aumentou pelo segundo ano consecutivo em 2016. O percentual, que já tinha subido de 8,4\% para 10\% em 2015 , atingiu $11,2 \%$ no ano passado. O estudo considerou abaixo da linha da pobreza brasileiros com renda per capita menor que 230 reais por mês, categoria que abarca mais de 20 milhões de brasileiros.

O desemprego e, consequentemente, a possibilidade de passar por condições de pobreza é o principal motivador para a decisão dos funcionários de recuperar as empresas. As ERTs são sobretudo uma alternativa encontrada por esses funcionários para manter alguma estabilidade financeira. Talvez sem se dar conta disso, esses trabalhadores, ao darem continuidade às operações dessas organizações recuperadas, podem auxiliar a economia caso isso aconteça em uma grande escala. Pois, trata-se de empresas que estão inseridas no mercado e podem influir em alguns indicadores, como o desemprego, a diminuição da pobreza, e até mesmo um eventual aumento do PIB, se essas empresas conseguirem se manter produtivas.

Como consequência da diminuição da produção, o país encontra-se sem dinheiro. Sem suporte financeiro para pagar suas contas, o Brasil aumenta sua dívida pública, que de acordo com o Tesouro Nacional alcançou em julho de 2017 cerca de 3,35 trilhões de reais. Ao longo de 2016, a dívida aumentou $11,42 \%$, e as expectativas apontadas pelo Tesouro Nacional para o fim do ano são negativas: projeta-se um aumento de 17,28\% em relação ao valor fechado em 2016 e estima-se que ela pode chegar a 3,65 trilhões de reais no fim de 2017.

Os dados demonstram o momento crítico vivido pelo país, e essa situação é repercutida internacionalmente em importantes veículos de mídia que relatam a instabilidade política e a fragilidade econômica que vivemos. Será analisada a seguir a repercussão negativa do momento vivido pelos brasileiros através de alguns exemplos de como o Brasil está sendo noticiado em outros países.

$\mathrm{Na}$ Europa, alguns de seus principais jornais publicaram sobre o assunto ao longo deste ano. Um dos periódicos de maior circulação no continente, o jornal inglês The Guardian afirma em reportagem divulgada em julho que "desemprego e instabilidade social ameaçam um indesejável retorno ao passado em um país que já foi visto como modelo para economias emergentes, mas é afetado pela recessão". Em junho de 2016, o francês Le 
Monde divulgou uma matéria com o seguinte título "Enfraquecido por uma crise econômica sem precedentes e um interminável escândalo de corrupção, o 'gigante' perdeu seu crédito", na qual explica possíveis razões e soluções para a crise em nosso país.

O principal jornal argentino, o Clarín, destacou alguns dados negativos do Brasil em matéria publicada também junho deste ano. O veículo destaca que, desde maio de 2016, a economia brasileira declinou cerca de 2,23\% e aborda a instabilidade política vivenciada no país, além de outros dados econômicos brasileiros.

Outro marco de notabilidade internacional ocorrido no Brasil é o baixo grau de investimento no país. Esta análise do grau de investimento é realizada por três agências internacionais - Fitch Rating, Moody's e Standard \& Poors - e tem o intuito de classificar a capacidade do país de conseguir honrar suas dívidas. Notoriamente sem dinheiro e endividado, o Brasil, que em 2015 era classificado como um bom pagador por todas as agências, em 2017 tem sua nota rebaixa pelas mesmas e é classificado hoje como "categoria de especulação, baixa classificação". Após repercussões internacionais sobre a instabilidade política e econômica, a queda no grau de investimento no país evidencia a dificuldade de obtenção de investimentos externos que a nação possui.

Como citado anteriormente, além da fragilidade econômica, há uma notável instabilidade política no Brasil. A troca de presidente ocorrida de maneira atípica em 2016, tendo este, de acordo com pesquisa realizada pela Ipsos Public Affairs em junho deste ano, a reprovação de $94 \%$ da população, possuindo ainda, de acordo com a consultoria Eurasia Group, o título de presidente mais impopular do mundo. Somado a isso, encontram-se em nosso país diversos escândalos de corrupção, dentre outros elementos, que reforçam a instabilidade do momento brasileiro. Essa situação foi exposta em matéria publicada em junho no jornal de maior influência no mundo, o New York Times. Com o título "Liderança política quebrada no Brasil", o periódico americano evidencia a turbulência política que vivemos.

Apesar de ser necessário entender o cenário político atual, não faz parte do intuito deste artigo trazer um posicionamento sobre questões políticas nem apontar culpados para a crise. É importante citar o que está acontecendo nesse âmbito, pois é possível que haja uma ligação entre economia e política, sobretudo porque essa instabilidade pode afastar investidores no país à medida em que o Brasil perde força e confiança no cenário mundial, além de aumentar a descrença da população sobre uma expectativa de melhora econômica.

A imprevisibilidade da economia não nos permite obter uma previsão com grande precisão sobre como serão os próximos anos no país. Houve algumas mudanças positivas ao longo do ano, como a diminuição da inflação, que de acordo com um levantamento emitido pelo Banco Central divulgado em outubro, será 2,95\% em 2017, valor muito inferior ao de 6,29\%, ocorrido em 2016. Há também uma previsão de crescimento do PIB: o IBGE 
afirma que houve crescimento de $1 \%$ no primeiro semestre deste ano e $0,2 \%$ no segundo. Além desses fatores, como citado anteriormente, houve uma pequena redução no número de desempregados.

Apesar de um pequeno avanço econômico ocorrido em 2017, o cenário enfrentado ainda não é positivo, tendo em vista os diversos dados apresentados recentemente. É possível afirmar que o país enfrenta uma crise econômica. Diante disso, surge para um administrador a responsabilidade de uma reflexão e de um posicionamento crítico sobre as dificuldades enfrentadas na economia.

As maiores potências econômicas da atualidade já passaram por crises. Os americanos presenciaram, em 1929, a chamada Grande Depressão; os alemães também vivenciaram a pobreza após a Segunda Guerra Mundial. Cada nação que passou uma forte recessão econômica adotou uma política com o intuito de recuperar a estabilidade. Portanto, - Brasil precisa de alguma medida para superar este momento. Para isso, veremos através de conceitos e experiências em recuperação de empresas e autogestão, adaptando e contextualizando o ocorrido com o cenário brasileiro atual - a possibilidade de utilizar essas práticas como uma alternativa sustentável para amenizar a instabilidade enfrentada pelo Brasil. 


\section{A experiência brasileira}

Os primeiros casos de recuperação de empresas no Brasil ocorreram no início da década 1980. Devido à ausência de estudos na época, não é possível datar ao certo qual foi a primeira empresa recuperada, mas algumas pesquisas apontam que a Wallig Sul, em 1984, foi a primeira ERT brasileira (Henriques. 2014:204). Em relação a empresas que adotaram a autogestão, de acordo com a Anteag, o primeiro caso no país ocorreu no ano de 1991 em França, cidade localizada no estado de São Paulo.

É perceptível dentro do imaginário comum de um brasileiro que o conceito de recuperação de empresas e autogestão é pouco conhecido e difundido em nosso país. Existem algumas razões para o desconhecimento do tema. A Secretaria Nacional de Economia Solidária (Senaes), por exemplo, que é considerada um dos principais aparatos do Estado sobre o tema, não fornece informações sobre o mapeamento dessas empresas no Brasil e tampouco esclarece algo sobre seus conceitos. Para Filho (1996:10) no Brasil não há uma política oficial de apoio à autogestão, que hoje se limita à concessão de crédito para investimento pelo BNDES. Henriques (2014:204) afirma que esse empréstimo é difícil de ser obtido, visto que as exigências impostas para a obtenção desse recurso impossibilitam que a maior parte dessas organizações realize essa operação.

A principal fonte sobre as empresas recuperadas e autogeridas no Brasil surgiu em uma recente pesquisa realizada no ano de 2013 por estudiosos do assunto de dez universidades, conforme citado anteriormente. Foi feito um mapeamento dessas empresas e, a partir de entrevistas, foram fornecidos dados sobre o funcionamento delas na atualidade. Participaram também dessa pesquisa o Sistema Nacional de Informações em Economia Solidária (Sies), a Associação Nacional dos Trabalhadores em Empresas de Autogestão e Participação Acionária (Anteag) e a Central de Cooperativas e Empreendimentos Solidários (Unisol).

Ao longo deste artigo serão apresentados alguns dos resultados dessa pesquisa, além de uma contextualização do conceito de autogestão e recuperação de empresas e uma análise do funcionamento dessas organizações sob a ótica da administração.

Primeiramente, para que seja possível uma maior compreensão desses conceitos, serão expostos a seguir os critérios que foram utilizados para que as empresas pudessem ser enquadradas como autogeridas e recuperadas. A partir dessas informações será 
possível adentrar a teoria e entender melhor a correlação entre a recuperação de empresas e a autogestão.

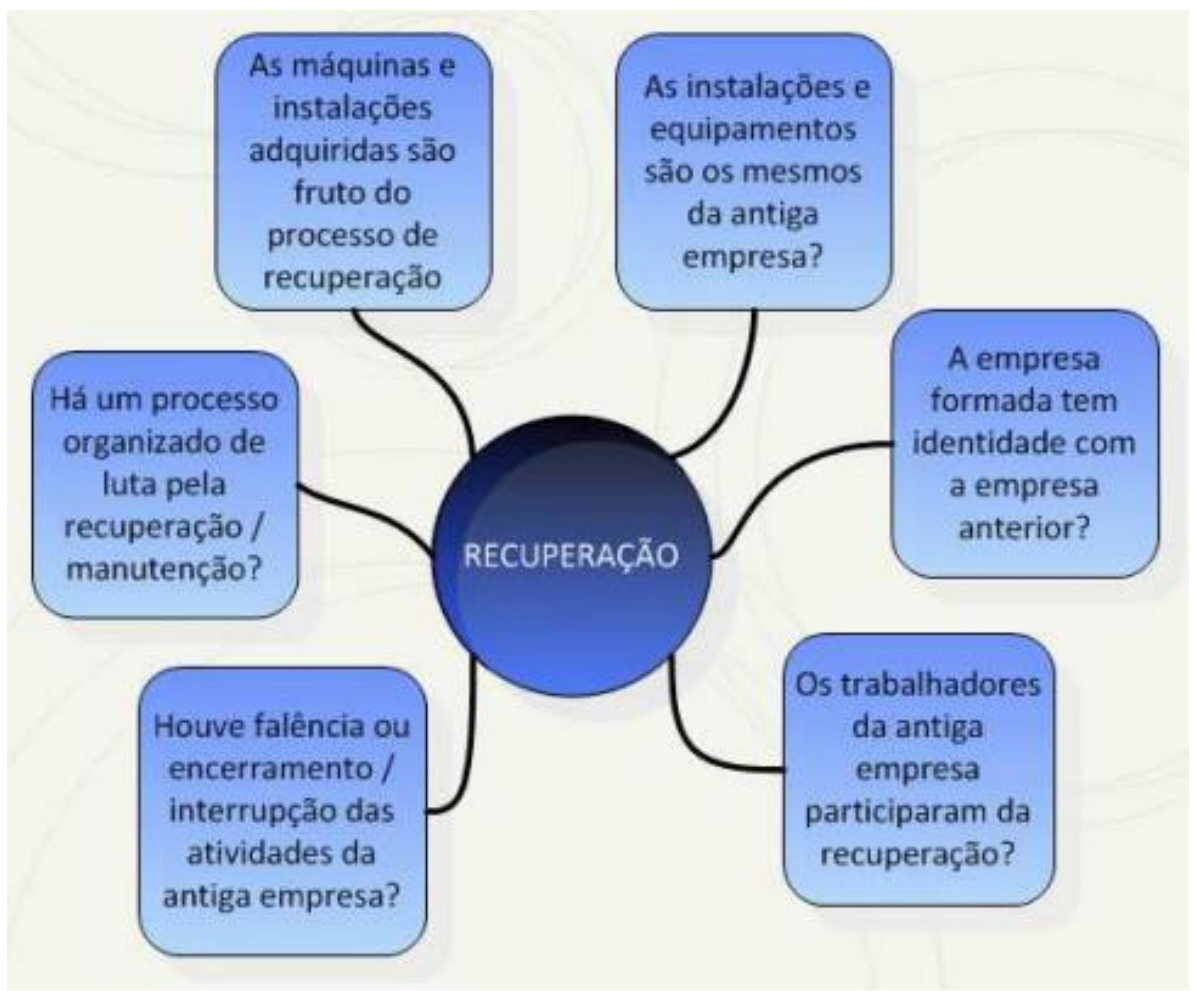

Figura 1 Critérios para definição de uma empresa recuperada por trabalhadores.

Fonte: Henriques (2013:31).

$\mathrm{Na}$ legislação brasileira, não existe uma classificação formal para empresas recuperadas por trabalhadores, ou seja, o conceito de ERT não pode ser percebido nas possíveis formas jurídicas que uma organização pode se declarar. Torna-se, portanto, difícil e subjetivo catalogar esses empreendimentos.

Outro fator que limita a qualificação de uma organização como ERT é a falta de uniformidade no processo de recuperação. Como mostrado anteriormente, a busca pela recuperação de uma empresa em processo de falência é oriunda da tentativa dos trabalhadores de manter seus empregos. Esses funcionários, ao adotarem tal medida, não necessariamente possuem uma noção clara das teorias que permeiam esse conceito, e a luta pela manutenção de seus cargos pode não ocorrer a partir de um processo ideológico, mas sim através de uma tentativa de conservação de seus cargos.

A falta de padronização nos processos de recuperação no Brasil é acentuada pelo pouco conhecimento que a população possui sobre esse fenômeno. A principal entidade que acolhe essas organizações no país é a Anteag. Esta, apesar de realizar pesquisas 
sérias, não consegue fornecer uma maior integração entre as ERTs brasileiras, que pouco se comunicam e, em sua maioria, funcionam de forma isolada.

A subjetividade da conceituação dá margem para diferentes resultados em mapeamentos sobre empresas recuperadas. No Brasil ocorreram alguns mapeamentos de menor expressão sobre essas organizações, e os resultados apresentaram algumas variações. Após a leitura de diferentes pesquisas sobre essas empresas, e considerando a seriedade dos envolvidos nelas, o mapeamento realizado por Anteag, Unisol, Sies e pesquisadores de dez universidades brasileiras será o referencial principal adotado como referência ao longo deste artigo.

Diante das limitações no processo de categorização dessas empresas, o mapeamento das ERTs brasileiras adotado neste artigo utilizou como parâmetro as seis premissas que foram mostradas na Imagem 3.1. Primeiramente, é levantado um questionamento acerca da manutenção da identidade da empresa, ou seja, deve haver uma continuidade nas operações. Caso a recuperação seja seguida de uma transformação radical em todo o processo produtivo, com novas máquinas e ativos físicos e intangíveis incoerentes com o que a organização possuía no momento anterior ao da recuperação, este empreendimento não será caracterizado dentro do levantamento feito como uma ERT. As outras premissas adotadas referem-se à necessidade de uma participação ativa dos empregados nesse processo, pois estes devem ser os protagonistas da recuperação. Ademais, é imprescindível que as empresas recuperadas tenham surgido após um momento de falência ou interrupção das atividades.

Haverá a seguir uma elucidação sobre os principais conceitos relacionados a autogestão, sendo necessário uma breve análise da evolução dos modelos de gestão na administração. Será apresentado também o knowhow que país possui nesse modelo, as premissas criadas para a classificação de uma empresa autogerida e posteriormente a correlação que a recuperação de empresas e a autogestão possuem.

Ao longo dos últimos séculos ocorreram várias mudanças na administração. A partir do século $\mathrm{XX}$, a administração começa a ser estudada e conceituada com teóricos como Fayol e Taylor. Tendo em vista a dinamicidade das relações de produção, tornam-se necessárias adaptações e reflexões sobre novos modelos a serem estudados. Por exemplo, durante as primeiras décadas do século XX, a Administração Científica era o modelo de administrar mais comum entre as empresas. Posteriormente, com o intuito de entender melhor as relações entre os funcionários, a Teoria das Relações Humanas começa a ganhar força, acarretando alterações no processo hegemônico anterior.

Apesar de geralmente existir uma cultura de gestão dominante no universo empresarial, há espaço para repensar modelos no intuito de adaptar-se a novas oportunidades. A autogestão, apesar de pouco difundida dentro da administração, tem sido 
adotada por diversas cooperativas, que posteriormente serão melhor explicadas, como uma forma mais viável para o desempenho de seus negócios.

Dentre os diversos teóricos que apresentaram importantes ideias para o universo de uma organização, destaca-se para este artigo Robert Owen. Trata-se de um reformista social inglês que fazia críticas a modelos de produção pouco democráticos. Owen é responsável pelo surgimento de estudos mais profundos sobre o cooperativismo, um conceito que será melhor abordado posteriormente.

A Imagem 3.2, que será encontrada a seguir, apresenta os parâmetros utilizados para identificar empresas autogeridas. Entre os elementos utilizados para essa classificação está a autodeclaração. Isso se deve à subjetividade que este conceito apresenta. As outras premissas referem-se essencialmente à necessidade de uma postura com seus stakeholders coerente com a ideologia democrática do conceito, a participação de todos os funcionários na tomada de decisão e a abertura para a contratação de novos sócios. Essas foram as premissas utilizadas nesta pesquisa, mas é importante entendermos que essas informações podem apresentar variações, e a classificação de uma empresa autogerida não está necessariamente limitada às premissas adotadas.

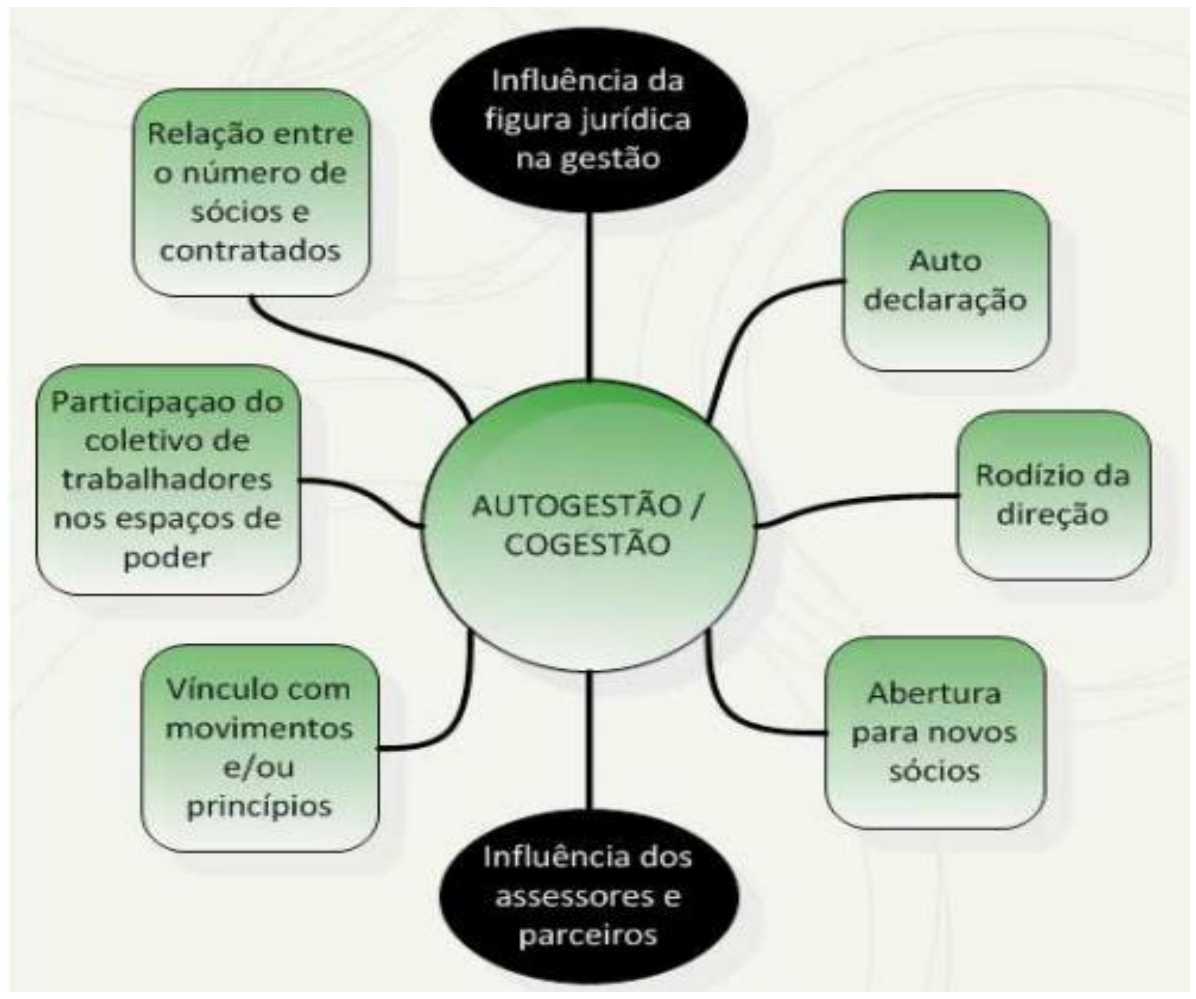

Figura 2 Critérios para definição de uma empresa autogerida.

Fonte: Henriques (2013:33). 
É necessária ainda a compreensão de que a autogestão não é obrigatoriamente a causa para a recuperação de empresas, e sim uma solução para a eficiência da produção delas. De acordo com Linhares (2013:127):

a autogestão das empresas recuperadas não é revolucionária, mas sim reformista. Não se trata, pelo menos em primeiro momento, de construção de uma nova ordem social ou de um novo modo de produção, mas da melhoria da eficiência da empresa no âmbito do capitalismo, como forma de viabilizar a dignidade da existência do trabalhador.

Após o aprofundamento conceitual sobre os objetos de estudo deste artigo, serão apresentadas as principais mudanças ocorridas nessas empresas após sua recuperação. Como dito anteriormente, a definição de cooperativas, sendo iniciada a partir de estudos de Robert Owen, possui muita relação com a identidade dessas empresas estudadas, visto que são tomadas algumas mudanças nas organizações que apresentam essa forma jurídica. Os dados coletados na pesquisa afirmam que há uma predominância entre as ERTs que adotaram a forma jurídica de cooperativa (85\%), seguidas de empresas (10\%), associações (3\%) e um caso de comissão de fábrica (2\%) (Henriques, 2013:61).

Além dos aspectos legais que apresentam, as cooperativas possuem algumas características que fomentam a democracia na organização, apresentando assim uma conexão maior com as ideias propostas por Owen e as práticas de empresas autogeridas.

O fato de a maioria das empresas se organizar em cooperativas nos ajuda a compreender a relação que as ERTs possuem com a autogestão, visto que "a natureza civil da cooperativa mostra que seu objetivo é a prestação de serviços para os associados e não a prestação de serviços para qualquer pessoa com a finalidade do lucro, mas para conceder melhores condições socioeconômicas para seus associados" (CARDONE, 2007:31). Além disso, por determinações legais sobre o cooperativismo, ao assumir essa forma jurídica as organizações são obrigadas a realizar assembleias gerais no mínimo uma vez por ano. Nessas assembleias, algumas decisões estratégicas para a empresa são discutidas de maneira democrática.

Com a ausência de um sócio majoritário, essas cooperativas são obrigadas a repensar seus modelos de gestão, e $92 \%$ das empresas entrevistadas afirmam que são autogeridas (HEN RIQUES, 2013:10). Ou seja, a autogestão é a alternativa de gerenciamento comumente adotada pelas ERTs, e por isso esses dois conceitos andam interligados.

A relação de pertencimento dos trabalhadores com a empresa pode ser vista na pesquisa realizada por Ferreira (2015) sobre o funcionamento de organizações autogeridas 
oriundas de um processo de recuperação. De acordo com Ferreira (2015:40), "Eles se definem como trabalhadores; trabalhadores autogestionários, trabalhadores associados, trabalhadores cooperativados, mas não como empregados, patrões ou empresários ou meio trabalhadores, meio empresários". Ou seja, existe uma relação entre os trabalhadores com suas empresas que não se restringe às dinâmicas usuais das relações de trabalho.

Após essa elucidação acerca das teorias que permeiam esses dois conceitos, tornase necessária a compreensão do funcionamento prático dessas organizações. O processo de recuperação de uma empresa não acontece de forma homogênea e não há uma maneira padrão de conduta para aqueles que desejam dar continuidade a empresas prestes a fecharem, mas serão apresentados os procedimentos comumente adotados pelas ERTs.

O primeiro passo para o processo de recuperação é uma tentativa de acordo entre os funcionários e os sócios. Com muitas dívidas, dentre elas algumas trabalhistas, os executivos precisam de dinheiro para conseguir honrar com esses débitos. Uma saída mais prática para esse processo é o perdão das dívidas trabalhistas aos empregados em troca da posse da empresa. Nos casos em que a dívida com os funcionários seja muito inferior aos bens físicos da empresa, os funcionários podem adquirir para si alguns dos débitos do antigo sócio como forma de tornar esse trade-off mais viável para ambos.

Essa prática seria facilitada caso houvesse alguma legislação com o intuito de auxiliar essa negociação. A falta de uma regularização legal que promova um maior entendimento nesse processo dificulta a recuperação de empresas que, em alguns casos, pode ser marcada pelo uso de força, tanto no Brasil, em que ocorre em $36 \%$ dos casos (HENRIQUES, 2013:10), quanto em outros países.

O principal apoio fornecido a essas ERTs para que esse processo ocorra de forma mais harmônica vem dos sindicatos. Os aparatos estatais não possuem muito reconhecimento entre os funcionários das organizações recuperadas, conforme é mostrado na Imagem 3.3, em que os trabalhadores de ERTs citaram a origem dos apoios que receberam. 


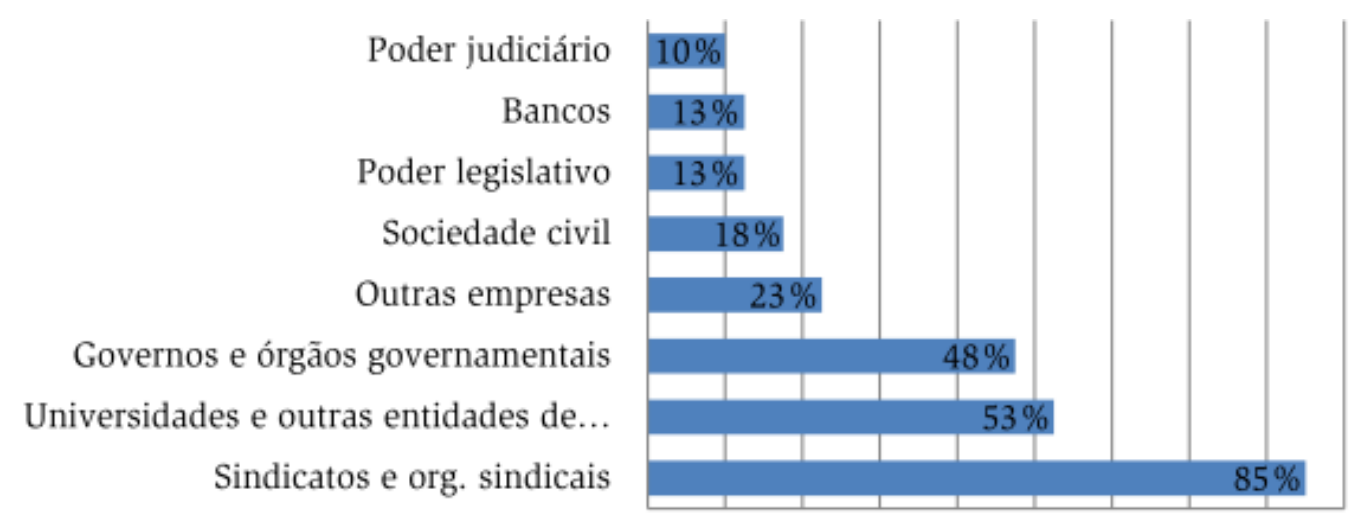

$0 \% 10 \% 20 \% 30 \% 40 \% 50 \% 60 \% 70 \% 80 \% 90 \%$

Gráfico 2 Principais fontes de apoio das ERTs brasileiras.

Fonte: Henriques (2013:57).

Para fornecer um conhecimento mais prático sobre as empresas recuperadas, será apresentado um pouco sobre quais são essas empresas no Brasil e como elas se diferenciam das demais organizações que não são oriundas de um processo de recuperação e tampouco adotam uma política de autogestão.

Conforme citado anteriormente, na pesquisa realizada com o intuito de mapear as ERTs brasileiras foi identificada a presença de 67 empresas recuperadas por trabalhadores que ainda se encontram em atividade no Brasil. Além destas, foram identificadas 78 ERTs que faliram ou se converteram em empresas privadas comuns. A seguir encontram-se dados relativos à localização, ao número de funcionários, ao ramo de atuação e ao nome das empresas identificadas na pesquisa. 
\begin{tabular}{|l|l}
\hline$N^{\circ}$ & Listagem das Empresas Recuperadas por Trabalhadores no Brasil \\
\hline
\end{tabular}

1 CAEB - Cooperativa Agro-Extratativista Bom Destino (Bonal)

COOPEL - Cooperativa dos Agricultores e Pecuaristas da Regional do

2 Baixo Acre

3 CCLB - Cooperativa Central de Laticínios da Bahia

4 COOPERPLASTICO - Cooperativa de Reciclagem Plástica da Bahia

5 COOPERBEL - Cooperativa dos Produtores de Cerâmica

6 COOPERTEXTIL - Cooperativa de Produção Textil de Pará de Minas

COOPERTRIM - Cooperativa dos Trabalhadores da Ind. Metalúrgica de

Raul Soares

8 Exata Retífica Motores

9 Minas Brasil Retifica de Motores

10 Retífica São Bento

11 POLYUTIL S.A

12 Coobertores Parayba - Indústrias de Cobertores Parahyba Ltda

13 USINA CATENDE - Cooperativa Industrial Catende Harmonia

14 COOPERBOTÕES - Nova Diamantina

15 CFF - Cooperativa Friburguense de Ferramentaria

16 Colégio Graham Bell

17 COOPARJ - Cooperativa de Produção de Parafusos do Estado do R

18 GPCANTELMO

19 HAGA S/A Indústria e Comércio

20 COMTERN - Cooperativa Mista dos Têxteis do Rio Grande do Norte

21 COOTALL - Cooperativa Taquarense de Laticinios Ltda

ALUMIFER - Cooperativa Autogestionária de Trabalhadoresde Fundição

de Aluminio e Ferro Ltda

COOFITEC - Cooperativa de Trabalhadores Profissionais de Fiação e

Tecelagem

24 COOPECA - Cooperativa Caxias de Móveis

25 COOPEN - Cooperativa do Vestuario de Encantado Ltda

26 COOPERCANA - Cooperativa dos Produtores de Cana Porto Xavier Ltda

27 COOPEREI - Cooperativa de Produção Cristo Rei

COOPERLEO - Cooperativa Leopoldense dos Trabalhadores da Indústria

28 de Carnes e Derivados Ltda

Ltda

COOPERSPUMA - Cooperativa dos Trabalhadores na Indústria e

30 Comércio de Espumas Colchões em Tecidos de Gravatai

31 COOPHOTEL - Cooperativa Gaúcha de Hotéis e Turismo LTDA

32 COOTEGAL - Cooperativa Têxtil de Galópolis

33 COSIDRA - Cooperativa de Produção de Sistemas Hidraulicos Ltda.

34 CTMC - Cooperativa dos Trab. Metalúrgicos de Canoas

35 FUNDECCOOPE - Cooperativa Fundeccoope

36 CDM - Cooperativa de Produção Metalúrgica de Brusque

37 COOPERMAQ - Cooperativa de Máquinas e Equipamentos

38 COOPERMETAL - Cooperativa do Metal de Criciúma

39 COOPERMINAS - Cooperativa De Extração De Carvão

UNIPOL
Joinville

COOPERVEST - Cooperativa dos Profissionais de Fabricação de

41 Vestuário LTDA

42 CONES - Cooperativa Nova Esperança

43 Cooperativa Monte Sinai

44 Cooperativa Unimáquinas

45 COOPERAVI - Cooperativa de Produção Agropecuária de Itatiba

COOPERCAIXA-Cooperativa Paulistana de Produção de Chapas de

46 Papel Ond.

47 COOPERFOR - Cooperativa Industrial de Trabalhadores em Forjaria

48 COOPERINCA - Centro de Eventos Convenções e Lazer

COOPERLAFE - Cooperativa de Trabalho em Laminação Forjado

Especial

O COOPERSALTO - Cooperativa de Produção dos Metalúrgicos de Salto

COOPERTEX - Cooperativa Autogestionária Industrial dos

1 Trabalhadores Têxteis

COOPERTEXTIL - Cooperativa de Produção Textil São José (Cobertores

\begin{tabular}{l|l}
52 & Parahyba) \\
53 & COOPERTRATT - Coop. Ind. de Trab. Trat. Term.
\end{tabular}

54 COOPERVIGUE - Cooperativa Vitoriosos Guerreiros

COOPEVAL - Cooperativa de Produção de Embutidos da Região de

5 Valinhos

COPEMA - Cooperativa de Produção de Esquadrias de Aço e Alumínio

6 (COPRAM)

57 COPROMEM - Cooperativa de Produtos Metalúrgicos de Mococa

COVAL - Cooperativa de trabalho de profissionais do abate de animais

8 de Louveira

59 CSJ - Cooperativa de Produção e Serviços Metalúrgicos São José

60 FLASKÔ Embalagens Plásticas

61 HIDROCOOP - Cooperativa Industrial Hidrocoop

METALCOOP - Cooperativa de Produção Industrial de Trabalhadores

62 em Conf. Metais.

63 Metalúrgica Rio Grande

PLÁSTCOO

UNIFERCO - Cooperativa Indústria de Trabalho em Usinagem e

65 Fundição de Alumínio

UNIFORJA - Cooperativa Central de Produção Industrial de

66 Trabalhadores em Metalurgia

UNIWIDIA - Cooperativa Industrial de Trabalhadores em Ferramentas

67 de Metal Duro

\begin{tabular}{l|l|l} 
Estado & $\mathrm{N}^{\circ}$ de Trabalhadores & Setor
\end{tabular}

\begin{tabular}{|l|r|r} 
AC & $\mathrm{N}^{\circ}$ de Trabalhadores & Setor \\
\hline & 269 & Alimentício \\
\hline
\end{tabular}

AC

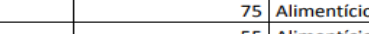

\begin{tabular}{|r|r}
55 & Químico \\
\hline
\end{tabular}

\begin{tabular}{l|r|l|} 
& 40 & Ceram \\
\hline
\end{tabular}

\begin{tabular}{|l|r|l|}
\hline MG & 23 & Metalúrgico \\
\hline
\end{tabular}

\begin{tabular}{|r|l} 
MG & 8 Metalúrgico
\end{tabular}

\begin{tabular}{r|r|l} 
MG & 12 & Metalúrgico \\
\hline
\end{tabular}

\begin{tabular}{|r|r|l}
\hline & 94 & Quimico \\
\hline
\end{tabular}

\begin{tabular}{|l|r|l|}
\hline$P E$ & 130 & Têxtil \\
\hline & 1000 & Agroindustrial \\
\hline
\end{tabular}

\begin{tabular}{l|r|l}
10 & Químico \\
\hline & 51 & Metalúr \\
\hline
\end{tabular}

\begin{tabular}{r|r|l} 
RJ & 42 & Educacional \\
\hline
\end{tabular}

\begin{tabular}{l|r|l}
$R J$ & 28 & Metalúrgico \\
\hline JJ & 48 & Metalurgo
\end{tabular}

\begin{tabular}{|r|r|l|}
\hline RJ & 48 & Metalúrgico \\
\hline
\end{tabular}

\begin{tabular}{|r|r|l} 
RN & 38 & Têxtil \\
\hline
\end{tabular}

\begin{tabular}{|l|r|l|} 
RS & 115 & Alimentício \\
\hline RS & 28 & Metalúrgico \\
\hline
\end{tabular}

\begin{tabular}{l|r|l} 
RS & 36 & Têxtil \\
\hline
\end{tabular}

\begin{tabular}{l|l|l} 
& 36 & Têxtil \\
\hline RS & 80 & Moveleiro \\
\hline
\end{tabular}

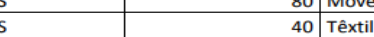

\begin{tabular}{|r|r|l|}
\hline & 283 & Agroindustrial \\
\hline
\end{tabular}

\begin{tabular}{|r|l|l} 
& 59 & Alimentício \\
\hline
\end{tabular}

\begin{tabular}{l|r|l}
3328 & Calçados \\
\hline
\end{tabular}

\begin{tabular}{l|r|l} 
& 7 & Têxtil \\
\hline
\end{tabular}

\begin{tabular}{l|r|r}
26 & Hoteleiro \\
\hline & 123 & Têtil \\
\hline
\end{tabular}

\begin{tabular}{|r|r|}
21 & Metalúrgico \\
\hline
\end{tabular}

\begin{tabular}{l|r|l} 
& 245 & Metalúrgico \\
\hline
\end{tabular}

\begin{tabular}{l|r|l} 
& 12 & Metalúrgico \\
\hline C & 70 & Metaúrgico
\end{tabular}

\begin{tabular}{l|r|l} 
& 70 & Metalúrgico \\
\hline C & 195 & Metalúrgico \\
\hline
\end{tabular}

\begin{tabular}{l|r|l} 
& 720 & Mineraçă \\
SC & 49 & Químico \\
\hline
\end{tabular}

\begin{tabular}{l|r|l} 
& 115 & Têxtil \\
\hline EE & 274 & Textil
\end{tabular}

274 Têxtil

12 Alimentício

\begin{tabular}{|l|l}
\hline Metalúrgico \\
\hline
\end{tabular}

\begin{tabular}{l|r|l} 
& 320 & Alimentício
\end{tabular}

110 Papeleiro

\begin{tabular}{|r|r|l} 
& 224 & Metalúrgica \\
\hline & 15 & Hoteleiro
\end{tabular}

\begin{tabular}{l|r|l}
58 & Metalúrgico
\end{tabular}

\begin{tabular}{l|l|l} 
& 88 & Metalúr \\
\hline P & não informou & Têxtil
\end{tabular}

\begin{tabular}{|l|r|l}
\hline SP & 152 & Têxtil \\
\hline
\end{tabular}

\begin{tabular}{|r|r|l|}
\hline PP & 133 & Metalúrgico \\
\hline & 34 & Químico \\
\hline
\end{tabular}

\begin{tabular}{l|r|l} 
SP & 170 & Alimentício \\
\hline
\end{tabular}

\begin{tabular}{|l|l|l}
\hline$P$ & 40 & Metalúrgico \\
\hline
\end{tabular}

\begin{tabular}{l|r|l} 
& 516 & Metalúrgico
\end{tabular}

\begin{tabular}{l|r|l} 
SP & 240 & Alimentício \\
\hline
\end{tabular}

\begin{tabular}{|r|r|l} 
& 381 & Metalúrgico \\
\hline SP & 79 & Químico \\
\hline
\end{tabular}

\begin{tabular}{|l|r|l|} 
SP & 35 & Metalúrgico \\
\hline
\end{tabular}

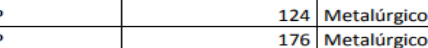

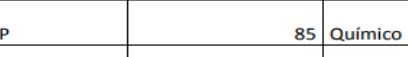

\begin{tabular}{l|l|l}
\hline$P$ & 32 & Metalúrgico \\
\hline
\end{tabular}

\begin{tabular}{|r|r|l}
\hline$P$ & 202 & Metalúrgico
\end{tabular}

Figura 3 Listagem das ERTs brasileiras.

Fonte: Henriques (2013:249-251) 
Primeiramente, é notável uma heterogeneidade nas empresas em relação à sua localização, ao seu tamanho e ao seu setor. As empresas podem ser grandes (6,1\%), de médio porte $(33,3 \%)$ e de pequeno porte $(60,6 \%)$, de acordo com a classificação estabelecida pelo IBGE. Elas estão localizadas em quatro das cinco regiões do país e são bem distribuídas ao redor do território nacional. Em relação aos setores de atuação, podemos perceber que essas organizações estão presentes em ramos muito distintos, sendo trinta na metalurgia, onze no ramo têxtil, nove no setor alimentício e sete em indústrias químicas, além de atuações em hotelaria, indústria sucroalcooleira, educação, cerâmica, papel, calçados, mineração e novelaria.

O primeiro desafio das 67 empresas citadas é pensar como será estruturada a tomada de decisão na empresa. Os antigos sócios eram os donos do negócio e, portanto, donos do poder. Porém, com a ausência deles, esse padrão precisa passar por uma reformulação.

Como é sabido entre aqueles que estudam administração, nem todas as pessoas possuem um perfil de liderança e se sentem aptas a se tornarem responsáveis pela tomada de decisão. Dentro das empresas recuperadas, existiam pessoas mais propícias a exercer esse cargo. Para isso, ainda que o poder seja descentralizado, tornou-se necessária a existência de uma estrutura hierárquica.

Na Flaskô Industrial de Embalagens Ltda., ERT localizada em Sumaré, no interior de São Paulo, que possui atualmente cerca de oitenta funcionários, a escolha dos representantes para a liderança é feita e através de conselhos de assembleias. De acordo com Delmondes (2009:39), a escolha ocorre da seguinte forma:

Os trabalhadores deverão discutir em assembleia para determinar quais pessoas poderão se responsabilizar por determinada função. [...] 0 conselho de fábrica formado por todos os trabalhadores de todos os setores da fábrica, será constituído anualmente, durante as assembleias gerais.

Devido à grande adoção da forma jurídica de cooperativas por parte dessas organizações, existe um modelo padrão de hierarquização. Essa estrutura pode ser percebida a partir do organograma genérico exposto na Imagem 3.5. 


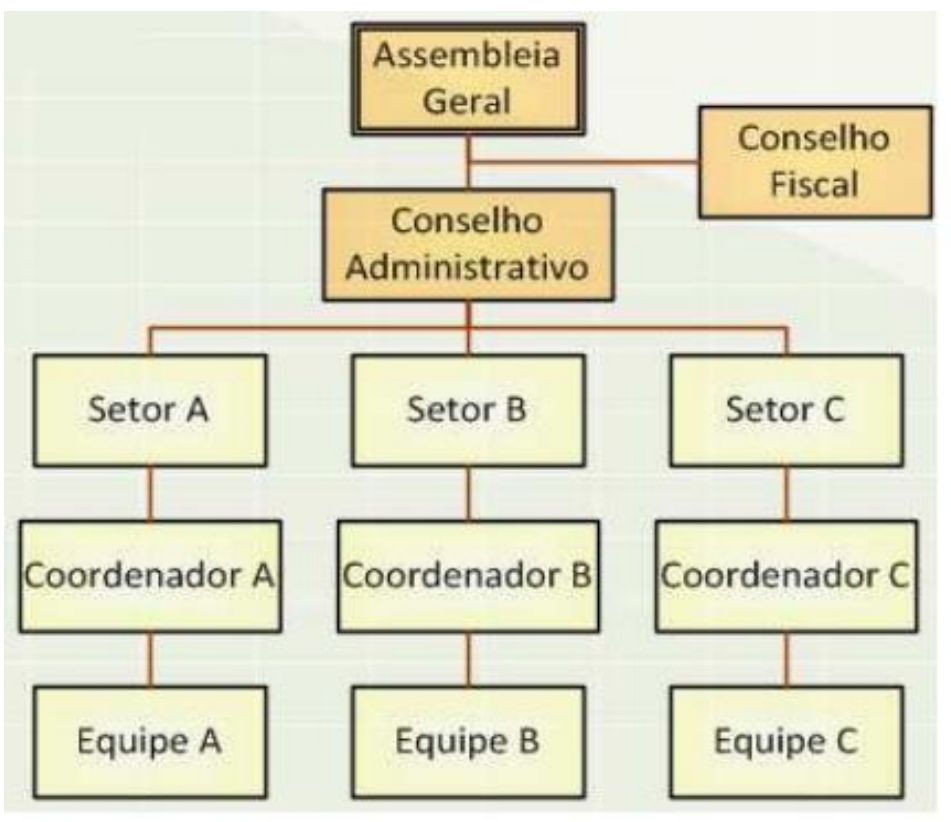

Figura 4 Organograma genérico de uma ERT.

Fonte: Henriques (2013:115).

$\mathrm{Na}$ Assembleia Geral, todos os trabalhadores são ouvidos e algumas decisões estratégicas da empresa são tomadas em conjunto por todos os seus representantes. Os conselhos são formados a partir de escolhas democráticas entre os funcionários, e os membros deste grupo detêm uma visão mais holística sobre o ambiente empresarial. A divisão que ocorre, classificada no organograma como $A, B$ ou $C$, não possui um modelo de departamentalização específico - a decisão fica a critério das empresas, e a escolha dos coordenadores/gerentes é feita entre os trabalhadores de acordo com critérios como o relacionamento, a capacidade técnica, o tempo de trabalho na empresa, entre outros fatores.

Após a organização da estrutura de poder, algumas medidas são tomadas, dentre elas a política de remuneração. É possível dizer que não há um padrão único e a disparidade entre a maior e a menor remuneração nessas empresas pode variar. Em alguns casos no Brasil e em ERTs de outros países, é adotada uma política de igualdade total nos salários, mas essa equidade não está presente na maioria dos casos.

A Imagem 3.6 apresenta os dados referentes às empresas brasileiras estudadas no mapeamento que foi citado anteriormente, demonstrando a diferença salarial entre os cargos de maior e menor remuneração. 


\begin{tabular}{|c|c|}
\hline Diferença entre o maior e menor salário & Número de empresas \\
\hline$<=2$ & 10 \\
\hline Entre 2 e 5 & 23 \\
\hline Entre 5 e 8 & 8 \\
\hline Entre 8 e 10 & 7 \\
\hline Maior que 10 & 2 \\
\hline
\end{tabular}

Tabela 1 Diferenças salariais do cargos de maior e menor remuneração.

Fonte: Henriques (2013:128).

Das 51 ERTs que forneceram informações referentes à política adotada, em 33 delas (65\% do total) não existem funcionários que recebam um salário que ultrapasse em mais de cinco vezes o menor salário. De acordo com a consultoria Mercer "o Brasil possui uma das dez maiores diferenças salariais do mundo entre o nível operacional e o alto escalão das empresas". Apesar de não existir um estudo que afirme como a maioria das organizações brasileiras faz essa distribuição, é possível perceber que as ERTs atuam de forma singular nesse sentido.

A tentativa de equalizar a remuneração nas empresas pode ser um fator limitante na contratação de novos funcionários, visto que a capacitação profissional pode ser seguida por uma maior expectativa de ganhos financeiros. Ou seja, pessoas que possuem um amplo conhecimento técnico exigem salários maiores para sua contratação. Ao adotar um teto salarial, as ERTs eventualmente não poderão arcar com o emprego desses funcionários mais qualificados. Porém, torna-se incoerente modificar essa estrutura de igualdade, pois isso feriria os princípios básicos relacionados à ideologia democrática, inclusiva e igualitária adotada por essas organizações. Portanto, a contratação de novos membros deve seguir uma ideologia que consiga se desvincular, ainda que pouco, da lógica do capital.

As mudanças feitas pelas empresas que adotam as práticas sugeridas neste artigo como alternativa à crise brasileira são percebidas pelos funcionários e refletidas no clima organizacional. Através de uma pergunta aberta realizada no mapeamento das ERTs brasileiras, os trabalhadores dessas organizações identificaram as principais mudanças ocorridas na nova forma de gestão que decidiram adotar, como mostra a Imagem 3.7. 


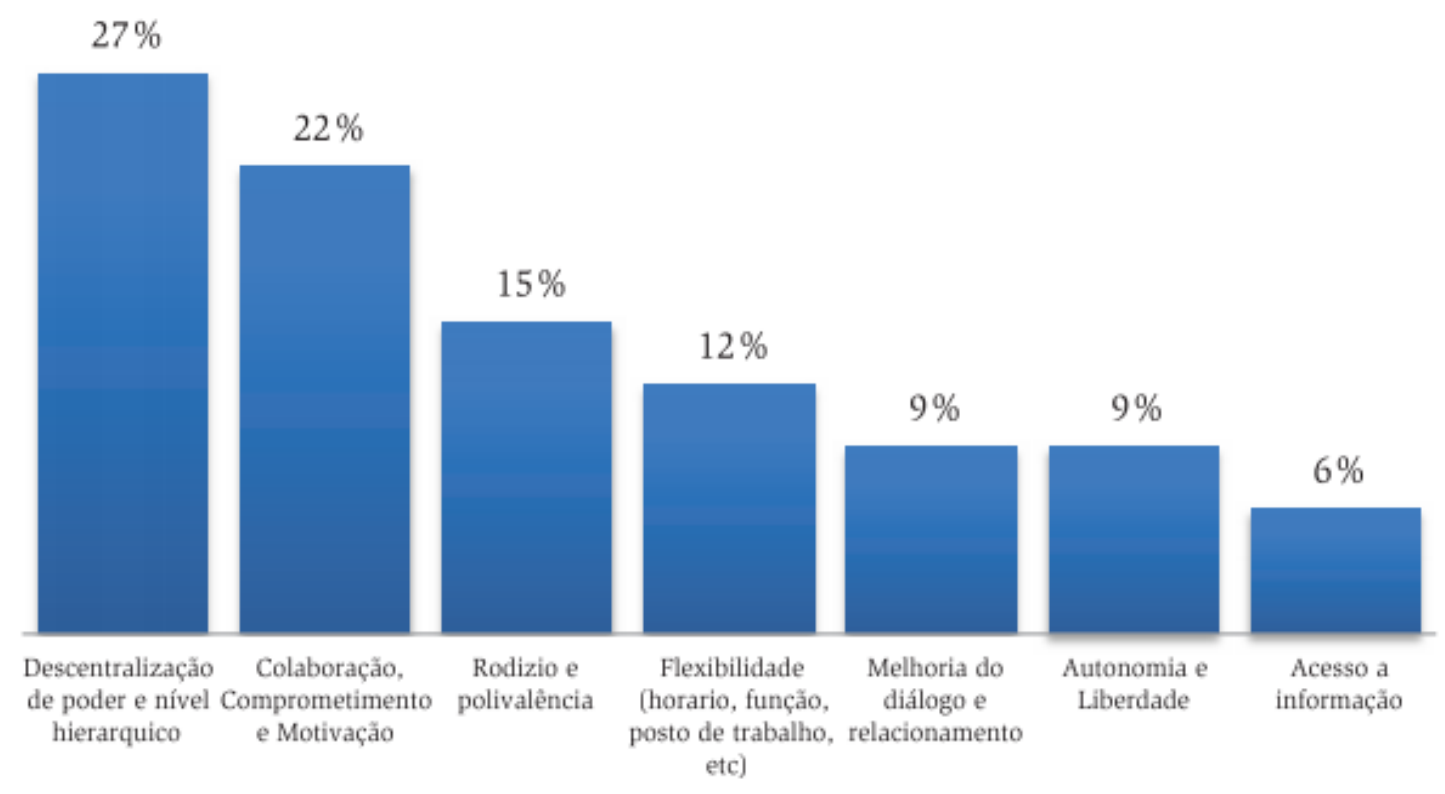

\section{Gráfico 3 Mudanças percebidas pelos trabalhadores das ERTs.}

Fonte: Henriques (2013:104).

É possível perceber que muitas das respostas possuem ligação direta com o clima organizacional da empresa. A percepção de aumento da motivação, comprometimento, flexibilidade, melhoria no relacionamento, autonomia e liberdade são indicadores positivos acerca do clima organizacional, algo que é buscado por inúmeras organizações, sendo este um ponto positivo sobre o funcionamento dessas ERTs.

A presença de pesquisas sobre ERTs dentro da administração é muito precária e, portanto, não é fácil encontrar dados sobre a produtividade e o desempenho econômico dessas empresas. Os estudos sobre recuperação de empresas e autogestão são geralmente desenvolvidos por outras áreas do conhecimento, e o entendimento desses conceitos ocorre majoritariamente de uma perspectiva ideológica, tendo como foco principal um entendimento alheio à competitividade de mercado dessas empresas.

Um dado importante sobre a eficiência das ERTs brasileiras encontra-se em um relatório divulgado pelo BNDES. Como vimos anteriormente, o banco fornece investimento a diversas organizações autogeridas. Destas, $70 \%$ conseguiram se manter adimplentes com o banco e apresentaram crescimento do resultado operacional superior a 100\% após o apoio.

Apesar dos inúmeros desafios enfrentados por essas empresas, sendo a falta de apoio o principal deles, as ERTs conseguem se manter produtivas no Brasil. Além da eficiência econômica que possuem - tendo em vista sua capacidade de manter-se competitivas no mercado -, essas organizações adotam medidas que são idealizadas por qualquer empreendimento, como um clima organizacional agradável e 0 alto comprometimento dos funcionários com o desempenho da empresa. 
O Brasil não é pioneiro dessa prática. Principalmente se comparadas às ERTs da Argentina, que serão explicadas melhor posteriormente, nossa experiência em recuperação de empresas não é tão eficiente ou numericamente grande. No entanto, elas obtiveram uma importância primordial na vida de milhares de trabalhadores no Brasil.

Como apresentado no capítulo anterior, o país enfrenta um cenário econômico muito alarmante, e sobretudo neste momento é instigante que o desempenho dessas ERTs seja acompanhado para uma reflexão crítica da importância que elas possuem em amenizar as consequências geradas pelo período de recessão enfrentado no país. 


\section{Experiências históricas em ERTs e autogestão}

Para Henriques (2014:30), a primeira experiência em autogestão ocorreu na França em 1871, na chamada Comuna de Paris, movimento caracterizado pelo domínio dos operários no poder após uma crise econômica e sobretudo política ocorrida na capital francesa. Porém, com o avanço da globalização e as mudanças nos padrões de produção, deve-se pensar em modelos de autogestão que estejam contextualizados com a competitividade do mercado atual, pois o intuito deste trabalho é trazer para a atualidade brasileira os eventos que serão descritos.

Deve-se observar o caso francês pelo pioneirismo no modelo de gestão, mas o evento ocorrido na França está inserido em um ambiente econômico muito diferente do que é enfrentado pelo Brasil no presente, principalmente pelo fato de a Comuna de Paris ser uma experiência socialista ocorrida na França. Trata-se, portanto, de um momento que apresentava necessidades diferentes das exigidas pelo modelo político econômico em que nosso país está inserido. De acordo com Ruggeri et al. (2014:32), os desafios da autogestão na atualidade são a adaptação às restrições e limitações impostas pelo capitalismo atual, um cenário certamente diferente daquele vivido pelos franceses no final do século XIX.

As empresas recuperadas por trabalhadores também são fenômenos antigos. Na Inglaterra, há 150 anos a recuperação de empresas já era algo usual (Henriques, 2013:10). Conforme dito anteriormente, ocorrem muitas mudanças no macroambiente em um século e meio, como aumento da globalização, mudanças nos padrões de consumo e nos meios de produção, entre outras. Por isso, utilizaremos neste artigo eventos ocorridos após a Terceira Revolução Industrial, com o intuito de relatar experiências em autogestão e recuperação de empresas que estejam inseridas em um contexto macroeconômico mais parecido com o que temos atualmente, tendo em vista que essa revolução, ocorrida na metade do século passado, é marcada pela globalização e maior inserção da tecnologia na produção, ou seja, um ambiente mais similar ao atual.

Será abordado primeiramente o episódio ocorrido na Argentina na virada do século, pois, apesar de haver casos de recuperação em momentos anteriores, foi a partir da experiência argentina que esse conceito começou a ser definido e estudado mais profundamente (Ruggeri, 2014:17). Após um momento de prosperidade econômica na primeira metade do século XX, a Argentina enfrentou uma intensa crise econômica na virada 
do século, possuindo, em 2001, um índice de desemprego de $21,5 \%$, com $31 \%$ da população enfrentando a pobreza em 1998 (Hopstein, 2007:76).

O país teve uma história importante em recuperação de empresas. Com o intuito de manter seus empregos, os argentinos deram continuidade à produção nas organizações que foram deixadas por seus sócios. De acordo com o jornal Página/12, em reportagem publicada no dia 20 de novembro de 2012, 70\% dos argentinos demonstravam-se cientes do conceito de recuperação de empresas, e $97 \%$ da população que conhecia o assunto avaliava essa prática de forma positiva. O país possui um total de 235 ERTs, e mais de 13.500 pessoas conseguiram recuperar seus empregos dessa forma (Ruggeri, 2014:23). De acordo com Ruggeri (2014:17), “A recuperação trata-se de uma saída para a economia do país, além da manutenção de postos de trabalhos que seriam perdidos".

Como vimos anteriormente, dados levantados pela equipe do Programa Facultad Abierta revelam que 60\% das ERTs argentinas surgiram entre os anos de 2001 e 2004 (Henriques, 2014:143), período em que a crise estava mais forte no país. A tentativa de manter o emprego é o estopim para um processo de recuperação das empresas, mas o caso argentino possui algumas especificidades que possibilitaram que o país alcançasse um número tão alto de ERTs.

Segundo Henriques (2014:154 apud Ruggeri, 2011), 85\% das ERTs argentinas disseram ter recebido algum benefício do Estado. Dentre as medidas de apoio do governo está a reforma na Lei de Falências. Trata-se da Lei 25.563 de 02/2002, que possui como principal objetivo frear o alto índice de falências no país. O principal benefício dessa lei para as ERTs é o aumento do prazo de pagamento das dívidas adquiridas pelos antigos sócios da empresa, e após sua promulgação o número de falências no país caiu em $41 \%$ (Henriques 2014:152). Em 2011, houve uma nova alteração nessa lei, fornecendo aos trabalhadores prioridade na compra da empresa falida, desde que possuam um plano de viabilidade econômica viável (Henriques, 2014:154).

O apoio estatal foi algo essencial para o caso argentino. Nesse aspecto, ele se diferencia muito do ocorrido no Brasil. Porém, não foi apenas o Estado que auxiliou no processo: as ERTs argentinas possuíam grande integração, e o movimento ganhava força conforme as empresas compartilhavam suas experiências. Dentre os grupos de representação das empresas recuperadas na Argentina encontram-se o Movimento Nacional de Fábricas Recuperadas (MNER), o Movimento Nacional de Fábricas Recuperadas por Trabalhadores (MNFRT), a Federación Argentina de Cooperativas de Trabajadores Autogestionados (Facta), a Unión Productiva de Empresas Autogestionadas (Upea), a Unión Obrera Metalúrgica (Uom) e a Associación Nacional de Trabajadores Autogestionados (Anta). Esses grupos atuavam para representar as empresas e foram responsáveis por fomentar casos de recuperação. Os movimentos tinham uma 
representatividade enorme na Argentina: 65 (41\%) das ERTs argentinas estavam vinculadas ao MNFRT e 23\% eram vinculadas ao MNER (Henriques, 2014:163). A atuação em conjunto forneceu maior força para cada uma das empresas, que, sozinhas, não conseguiriam obter tanto êxito.

Além da Argentina, outros países da América Latina, como Bolívia, Uruguai, Chile, Peru, Paraguai, Venezuela e México, tiveram experiências memoráveis em recuperação de empresas. Este processo deve-se sobretudo a uma alternativa encontrada por essas nações para recuperar-se dos efeitos de dificuldades econômicas, oriundas de eventos como a crise do petróleo em 1973 e os efeitos causados pelos movimentos ditatoriais que ocorreram na segunda metade do século passado.

No início deste século, o Uruguai enfrentou uma das maiores crises econômicas de sua história. Entre 35\% e 40\% das empresas uruguaias fecharam durante a crise que se instalou no país em 2002. Com o mesmo intuito dos argentinos, os uruguaios, em uma tentativa de manter seus postos de trabalho, recuperaram trinta dessas organizações em falência, resultando na manutenção do emprego de mais de 3.000 pessoas (Ruggeri et al., 2014:124). Para ajudar os trabalhadores, foi criado no país o Fundo de Desenvolvimento Nacional (Fondes). De acordo com Ruggeri et al. (2014:124), "O Fondes se cria como um decreto presidencial com objetivo de dar assistência e suporte financeiro a projetos produtivos priorizando empreendimentos com participação de seus trabalhadores na direção e capital das empresas, e em particular a modelos de autogestão". Esse fundo foi criado em 2011, durante o governo de José Mujica. Em entrevista realizada pelo jornal uruguaio El Observador em junho de 2017, um dos idealizadores do fundo, Carlos Aulet, diz que a prioridade do fundo deve ser "manter os postos de trabalho" e depois "ver quais medidas implementar para ajudar a melhorar a gestão, para que o dinheiro comece a ser devolvido".

Em 2004, na Venezuela, foi registrada a existência de dezenove ERTs, além de oitocentas cooperativas. Naquele ano, foi criada dentro do Ministério de Economia Popular (Minep) uma divisão para falar desse tema e auxiliar empresas que precisavam de suporte. Como resultado, o número de cooperativas no país em 2014 era superior a 70.000 organizações (Henriques, 2014:49). No caso venezuelano em específico, houve um processo de estatização desses empreendimentos, e atualmente todos são controlados pelo Estado. No entanto, a apropriação dessas organizações pelo poder público não será analisada neste artigo como uma possibilidade viável para uma melhora em nossa economia.

Em 1979, existiam no Peru 44 empresas recuperadas, com o total de 7.156 trabalhadores. Em 2015, eram totalizadas sessenta organizações recuperadas, que possuíam entre 7.000 e 9.000 funcionários (Henriques, 2014:47 apud Nascimento, 2015). 
É importante ressaltar que a recuperação de empresas não ocorreu apenas nos países latinos. Grandes potências mundiais também possuem em sua história a luta dos trabalhadores para continuar a produção de empresas e manter seus empregos. A União Europeia, com uma histórica economia estável, também possui experiências em recuperação de empresas. Na medida que este conceito ganhava notabilidade no continente europeu, começou a se difundir o: Employee Buyout (EBO). Trata-se de uma formalização do processo de compra da empresa pelos funcionários, presente em diversos países da Europa, sendo uma das maneiras de recuperação de empresas existente.

A chamada crise da dívida pública da zona do euro, ocorrida em 2009 abalou a economia de diversos países europeus. Dentre os países mais afetados estão a Grécia, que de acordo com reportagem publicada pela BBC precisou de um empréstimo de 110 bilhões euros do FMI para auxiliar sua recuperação. A Espanha, que junto com a Grécia é um dos dois países com maior desemprego na União Europeia, também precisou de um empréstimo do FMI, que, de acordo com o jornal O Estado de S. Paulo, totalizou 100 bilhões de euros.

Henriques (2014:47) afirma que "a crise que se intensificou a partir de 2010 para alguns países também deu origem a casos de recuperação de empresas na Europa, como na Grécia e na Espanha". Na Espanha, o Instituto de Ciências Económicas y de la Autogestión afirma que o país possui quarenta ERTs, mas ainda não é possível mensurar quantas surgiram em virtude da recente crise.

Na Grécia, ocorreu em 2016 um evento chamado Euromediterranean Workers Economy Meeting. O evento, que contou com trabalhadores da Itália, da Croácia, da Sérvia, da França, da Turquia, da Bósnia, da Espanha, da Alemanha e da Polônia, entre outros, abordou a recuperação de empresas a partir da análise de sucesso do caso argentino e discutiu a experiência dos países no tema.

Na Itália, o Ministério de Desenvolvimento Econômico revela que "A fim de promover o desenvolvimento econômico e o crescimento dos níveis de emprego no país, foi estabelecido o Decreto do Ministro de Desenvolvimento Econômico de 4 de dezembro de 2014". O objetivo dessa medida é o financiamento subsidiado para cooperativas. Os recursos oferecidos somam cerca de 9,8 milhões de euros e possuem um prazo máximo de dez anos para que o pagamento seja feito ao governo. $O$ ministério revela também que "O financiamento facilitado é concedido para suportar em todo o território nacional a criação de sociedades cooperativas, predominantemente constituídas por trabalhadores de empresas atingidas pela crise".

A maior potência econômica da atualidade, os Estados Unidos, também passou por um período de dificuldade econômica. De acordo com o Departamento de Comércio do país, em 2009 o PIB estadunidense contraiu-se 2,4\%, maior queda desde 1946. O desemprego 
também aumentou no país, de acordo com CIA World Factbook, o índice de desemprego nos EUA entre os anos 2008 e 2014 chegava a ser maior que o brasileiro.

No final do ano de 2008, quando a crise começava a aparecer nos Estados Unidos, a companhia americana Republic Windows and Doors, fundada em 1967, declarou falência. Após um processo longo e burocrático, os trabalhadores da organização uniram esforços para dar continuidade à produção da empresa, com a qual possuíam grande identificação. $O$ desfecho desse processo ocorreu apenas em 2012, quando a fábrica foi comprada por seus ex-funcionários e, sob a forma de uma cooperativa, foi criada a New Era Windows Cooperative. Essa cooperativa é o caso de recuperação em empresas americanas que obteve maior repercussão, e hoje ela é autogerida - toda tomada de decisão é feita de maneira democrática. Em seu site, a organização descreve sua história da seguinte maneira: "In 2008, the boss decided to close our windows factory on Goose Island and fire everyone. In 2012, we decided to buy the factory for ourselves and fire the boss. We now own the plant together and run it democratically. This is our story."

Ainda nos EUA, há algumas medidas adotas pelo governo que fomentam a autogestão. Filho (1996:22 apud Logue, s.d.:16) menciona que vinte estados americanos instituíram leis de incentivo à autogestão, sendo que oito deles montaram sistemas de apoio bastante desenvolvidos, com órgãos para a formação de mão de obra, treinamento gerencial e apoio ao crédito, dando base ao aparecimento de várias empresas.

A recuperação de empresas já faz parte da história de vários países. Como consequência desse processo, a autogestão também já é mundialmente debatida em vários âmbitos sociais. Existe um receio sobre como essas empresas conseguiriam funcionar sob moldes tão diferentes dos que são adotados tradicionalmente pelas organizações, porém vimos exemplos de empresas recuperadas funcionando em diversos países que possuem diferentes panoramas econômicos.

Podemos perceber uma forte ligação entre a recuperação de empresas com períodos de instabilidade econômica, que é o contexto que vivemos atualmente. As ERTs podem ter competitividade no mercado, tendo em vista o funcionamento dessas organizações em diferentes lugares do mundo, e possuem uma participação direta na manutenção do emprego de milhares de pessoas.

O posicionamento favorável adotado por diferentes países, que promoveram medidas como, por exemplo, o apoio ao crédito e a mudança em algumas leis com o intuito de auxiliar o desempenho de empresas autogeridas, traz a reflexão que essa pode ser uma atitude para o Brasil adotar. 


\section{Conclusões}

A administração possui como objeto principal de estudo as empresas, ou, utilizando um conceito mais moderno, as organizações. Portanto, é incoerente que a maioria das pesquisas sobre ERTs seja realizada por outras ciências que não possuem como foco principal de análise as empresas.

A partir do estudo de como funcionam as organizações, é necessário entender a tomada de decisão e os meios de gestão adotados pelas mesmas. A autogestão é um dos possíveis modelos a se adotar e é um conceito que se vincula ao objeto principal de estudo da administração. A ausência de estudos por representantes dentro dessa ciência sobre autogestão também se configura como algo incoerente, pois a administração deveria ser justamente a principal fonte de pesquisas sobre o tema.

Deve-se se questionar o porquê da ausência de debates dentro da administração sobre esses conceitos. Principalmente ao analisar uma mudança no modelo de gestão das empresas na atualidade, tendo em vista que o aumento de práticas que promovam maior sustentabilidade ambiental, empresarial, econômica e social têm sido uma tendência mundial. A sustentabilidade que o conceito de autogestão apresenta torna-o intimamente ligado a essa tendência buscada pelas organizações que não possuem somente o lucro como fonte de eficiência organizacional.

A existência de empresas recuperadas e, principalmente, a capacidade que elas possuem de se manter ativas e competitivas dentro do mercado, tanto no Brasil quanto no exterior, traz ao administrador a responsabilidade de compreender esses fenômenos.

Apesar de alguns ideais referentes a ERTs e autogestão terem surgido a partir de ideias socialistas, o fato de elas se inserirem dentro da lógica do capital - ou seja, competirem no livre mercado e se configurarem produtivas - não inviabiliza que seja feita uma análise dessas organizações dentro de uma perspectiva capitalista.

A recuperação de empresas está presente na história de diversos países com economias distintas. Como visto anteriormente, no país com o maior número de ERTs no mundo, a Argentina, $70 \%$ da população declara possuir conhecimento sobre recuperação de empresas e $97 \%$ dos que possuem algum conhecimento avaliam esse fenômeno de forma positiva.

Além de uma aprovação por parte da população, foi apresentado um posicionamento positivo por diversos governos, como na Itália, EUA, Argentina, Uruguai, entre outros. Essas 
medidas podem ser percebidas através da criação de leis de fomento a essas práticas como mudanças nas leis de falência, além da criação de fundos para auxiliar essas organizações -, esse panorama traz o questionamento sobre a viabilidade de o Brasil acompanhar esse processo.

Quando foi analisado a experiência brasileira, tornou-se possível perceber a eficácia que essas empresas possuem. As práticas democráticas adotadas por essas organizações foram refletidas no clima empresarial, tendo como principal consequência o aumento da motivação dos trabalhadores nessas empresas.

Ainda que de maneira restrita devido à pouca difusão que as ERTs possuem, elas já são mecanismo eficientes para amenizar as consequências de uma crise econômica. Ao fomentar essas práticas, abre-se espaço para que a recuperação de empresas ocorra em uma escola maior possibilitando assim a manutenção de empregos em escalas mais abrangentes.

Ao obliterar a importância que os fenômenos aqui descritos possuem como uma alternativa para amenizar as consequências da crise econômica vigente no Brasil, perde-se a oportunidade de salvar o emprego de milhões de brasileiros que perderam sua principal fonte de renda e, consequentemente, sua capacidade de consumo.

É importante ressaltar ainda que a volta desses trabalhadores ao mercado de trabalho não representa uma melhoria apenas para eles próprios e suas famílias. São pessoas que voltam a consumir e, portanto, dão mais movimento à economia à medida que, enquanto consumidores, fomentam as atividades de outras empresas, gerando assim uma diminuição da necessidade de novas demissões. Além disso, ao possibilitarem um aumento da produção do país, as ERTs criam uma eventual perspectiva de que isso possa ser revertido em um apoio ao crescimento do PIB.

Apesar de ser uma proposta pouco usual dentro dos moldes capitalistas, a recuperação de empresas e autogestão pode ser realizada, reaproveitada e contextualizada com o momento vigente. É necessário pensar além do óbvio e perceber que existem brechas tidas como anticapitalistas que podem surgir como alternativas cabíveis dentro desse modelo político-econômico para auxiliar seu funcionamento e, principalmente, aumentar a qualidade de vida de tantos brasileiros que estão precisando, e muito.

Este artigo discorreu uma contextualização teórica sobre a autogestão e a recuperação de empresas, junto como uma análise histórica sobre a implantação dessas teorias. As ERTs possuem uma capacidade de salvar empregos e dar continuidade à produção de empresas que não conseguiram se manter produtivas. O Brasil necessita de uma política de redução dos números de desempregados, além de um posicionamento sobre o grande aumento no número de empresas falidas e suas consequências. Assim, a 
recuperação em empresas, junto com a autogestão, podem ser mecanismos eficientes para auxiliar positivamente a economia brasileira e a vida de milhões de pessoas que aqui vivem. 


\section{Referências Bibliográficas}

ARCOVERDE, P. Brasil tem uma das maiores diferenças salariais entre a base e o topo. Valor Econômico, São Paulo, 28 maio 2013. Disponível em: http://www.valor.com.br/carreira/3141332/brasil-tem-uma-das-maiores-diferencas-salariaisentre-base-e-o-topo. Acesso em 9 nov. 2017.

BBC BRASIL. Entenda a crise da dívida da Grécia. S.I., 24 fev. 2012. Disponível em: http://www.bbc.com/portuguese/noticias/2012/02/120224_grecia_entendas_rp. Acesso em 9 nov. 2017.

BRAGA, P. FMI adverte Espanha sobre termos do empréstimo. O Estado de S. Paulo, 20 jul. 2012. Disponível em: http://economia.estadao.com.br/noticias/geral,fmi-adverte-espanhasobre-termos-do-emprestimo,120105e. Acesso em 9 nov. 2017.

CARDONE, V. Cooperativas de trabalho: legalidade e subsistência. São Paulo: Editora Antiqua, 2007.

DELMONDES, C.; LUCIANO, C. Flaskô: fábrica ocupada. São Paulo: Editora CEMOP, 2009.

DIÁRIO COMÉRCIO INDÚSTRIA E SERVIÇOS. Falências mudam na Argentina. S.I., 15 abr. 2011. Disponível em: http://www.dci.com.br/internacional/falencias-mudam-naargentina--id253081.html. Acesso em 9 nov. 2017.

FERREIRA, D. C. G. Fundação e funcionamento de cooperativas gastronômicas autogestionárias de Buenos Aires. Trabalho de Conclusão de Curso (Graduação em Gastronomia). Rio de Janeiro, UFRJ, 2016.

FOLHA DE S.PAULO. Desemprego recua para 12,6\% no trimestre e atinge 13,1 milhões. São Paulo, 29 set. 2017.2 Disponível em: http://www1.folha.uol.com.br/mercado/2017/09/1922851-brasil-tem-desemprego-de-126-notrimestre-ate-agosto-diz-ibge.shtml. Acesso em 9 nov. 2017. 
FILHO, F. P. Autogestão : promessas e desafios Rio de Janeiro : BNDES, 1996.

FRIAS, M. C. Número de empresas que pedem falência no Brasil sobe 12,2\% em 2016. Folha de S. Paulo, São Paulo, 10 jan. 2017. Disponível em: http://www1.folha.uol.com.br/colunas/mercadoaberto/2017/01/1848412-numero-deempresas-que-pedem-falencia-no-brasil-sobe-122-em-2016.shtml. Acesso em 9 nov. 2017.

GATINOIS, C. L'étoile pâlie du Brésil sur la scène internationale. Le Monde, 22 jun. 2016. Disponível em: http://www.lemonde.fr/idees/article/2017/06/22/l-etoile-palie-du-bresil-sur-lascene-internationale_5149099_3232.html. Acesso em 9 nov. 2017.

GOSMAN, E. La crisis política golpea la economía de Brasil: la actividad cayó 0,5\%. Clarín, 17 julho 2017. Disponível em: https://www.clarin.com/mundo/crisis-politica-golpea-economiabrasil-actividad-cayo_0_H14WhT8HZ.html. Acesso em 9 nov. 2017.

HENRIQUES, F. C. Autogestão em empresas recuperadas por trabalhadores. 1. ed. vol 4. Rio de Janeiro: Editora Insular, 2014.

Empresas recuperadas por trabalhadores no Brasil e na Argentina. Tese (Doutorado em Planejamento Urbano e Regional). Rio de Janeiro, UFRJ, 2013. Disponível em: http://objdig.ufrj.br/42/teses/794534.pdf. Acesso em 9 nov. 2017.

HENRIQUES, F. C. et al. As empresas recuperadas por trabalhadores no Brasil: resultados de um levantamento nacional. Mercado de Trabalho, Rio de Janeiro, n. 55, ago. $2013 . \quad$ Disponível em: http://www.ipea.gov.br/agencia/images/stories/PDFs/mercadodetrabalho/bmt55_econ02_em presas.pdf. Acesso em 9 nov. 2017.

Empresas recuperadas por trabalhadores no Brasil. 1. ed. Rio de Janeiro: Multifoco, 2013.

HOPSTEIN, G. A rebelião argentina: assembleias de bairro, piqueteros e empresas recuperadas. Rio de Janeiro: E-papers, 2007. 
JORNAL DO BRASIL. Temer é o presidente mais impopular do mundo, diz pesquisa. Rio de Janeiro, 20 out. 2017. Disponível em: http://www.jb.com.br/pais/noticias/2017/10/26/temer-eo-presidente-mais-impopular-do-mundo-diz-pesquisa/. Acesso em 9 nov. 2017.

JUVENAL, T. L. Empresas recuperadas por trabalhadores em regime de autogestão: reflexões à luz do caso brasileiro. Revista do BNDES, Rio de Janeiro, vol. 13, n. 26, p. 115138, dez. 2006.2 Disponível em: https://web.bndes.gov.br/bib/jspui/bitstream/1408/12353/1/RB\%2026\%20Empresas\%20Rec uperadas\%20por\%20Trabalhadores\%20em\%20Regime\%20de\%20Autogest\%C3\%A3o_Refl ex\%C3\%B5es\%20\%C3\%A0\%20Luz\%20do\%20Caso\%20Brasileiro_P_BD.pdf. Acesso em 9 nov. 2017.

LAPORTA, T.; SILVEIRA, D. PIB avança 0,2\% no 2ำ trimestre de 2017, diz IBGE. G1, 1 set. 2017. Disponível em: https://g1.globo.com/economia/noticia/pib-avanca-02-no-2-trimestrede-2017.ghtml. Acesso em 9 nov. 2017.

PIB do Brasil cresce 1\% no 1ํㅡㄹ trimestre de 2017, após 8 quedas seguidas. G1, 1 jun. 2017. Disponível em: https://g1.globo.com/economia/noticia/pib-do-brasil-cresce-10no-1-trimestre-de-2017.ghtml. Acesso em 9 nov. 2017.

MARTELLO, A. Dívida pública avança 3,22\% em junho, para $R$ \$ 3,35 trilhões. G1, 24 jun. 2017. Disponível em: https://g1.globo.com/economia/noticia/divida-publica-avanca-322-emjunho-para-r-335-trilhoes.ghtml. Acesso em 9 nov. 2017.

. Economistas do mercado veem menos inflação e alta maior do PIB em 2017 e

2018. O Globo, 2 out. 2017. Disponível em:

https://g1.globo.com/economia/mercados/noticia/economistas-do-mercado-veem-menosinflacao-e-alta-maior-do-pib-em-2017-e-2018.ghtml. Acesso em 9 nov. 2017

MINISTERO DELLO SVILUPPO ECONÔMICO. Nascita e sviluppo di società cooperative di piccola e media dimensione (Nuova Marcora). S.I. 27 jul. 2015. Disponível em: http://www.sviluppoeconomico.gov.it/index.php/it/incentivi/impresa/cooperative-nuovamarcora. Acesso em 9 nov. 2017

MIRAMAR, J. Fábricas recuperadas y autogestión en la nueva realidad de España. Estudios revista de pensamiento libertario, Madrid, 30 dez. 2012. Disponível em: http://estudios.cnt.es/fabricas-recuperadas-autogestion/. Acesso em 9 nov. 2017. 
NEW ERA WINDOWS COOPERATIVE. Our Story. S.I., s.d. Disponível em: http://newerawindows.com/about-us/our-story. Acesso em 9 nov. 2017.

PHILLIPS, D. 'People are getting poorer': hunger and homelessness as Brazil crisis deepens. The Guardian, 19 jul. 2017. Disponível em: https://www.theguardian.com/globaldevelopment/2017/jul/19/people-getting-poorer-hunger-homelessness-brazil-crisis. Acesso em 9 nov. 2017.

PINHEIRO, P. S. Brazil's Broken Political Leadership. The New York Times, 4 jun. 2017. Disponível em: https://www.nytimes.com/2017/06/04/opinion/brazil-president-temercorruption.html. Acesso em 9 nov. 2017.

ROCHA, A. Nível de reprovação a Temer atinge novo recorde e vai a 94\%, aponta pesquisa. O Estado de S. Paulo, 25 julho 2017. Disponível em: http://politica.estadao.com.br/noticias/geral,nivel-de-reprovacao-a-temer-atinge-novorecorde-e-vai-a-94-aponta-pesquisa,70001904288. Acesso em 9 nov. 2017.

RUGGERI, A. Que són las empresas recuperadas?. 1. ed. Buenos Aires: Ediciones Continente, 2014.

RUGGERI, A.; NOVAES, H. T.; SARDÁ DE FARIA, M. Crisis y augoestión en el siglo XXI. 1. ed. Buenos Aires: Ediciones Continente, 2014.

SALES, R. Desemprego no Brasil atinge a maior taxa desde 2012. Valor Econômico, 31 jan. 2017. Disponível em: http://www.valor.com.br/brasil/4853298/desemprego-no-brasil-atingemaior-taxa-desde-2012. Acesso em 9 nov. 2017.

SEBRAE NACIONAL. Cooperativa: o que é, para que serve, como funciona. S.I., s.d. Disponível em: https://www.sebrae.com.br/sites/PortalSebrae/bis/cooperativa-o-que-e-paraque-serve-como-funciona,7e519bda15617410VgnVCM2000003c74010aRCRD. Acesso em 9 nov. 2017.

SOUZA, M. PIB dos EUA teve em 2009 maior queda desde 1946. O Estado de S. Paulo, 20 jan. 2010. Disponível em: http://economia.estadao.com.br/noticias/geral,pib-dos-eua-teveem-2009-maior-queda-desde-1946,503615. Acesso em 9 nov. 2017. 
TOCAR, M. ¿E qué están los principales emprendimientos financiados por el Fondes? El Observador, 20 junho 2017. Disponível em:https://www.elobservador.com.uy/en-que-estanlos-principales-emprendimientos-financiados-el-fondes-n1087262. Acesso em 9 nov. 2017.

VALES, L. El valor de la economía que no sigue las lógicas del mercado. Página/12, Buenos Aires, 20 nov. 2012. Disponível em: https://www.pagina12.com.ar/diario/elpais/1-2081632012-11-20.html. Acesso em 9 nov. 2017.

VARANDA, A. P. M.; BOCAYUVA, P. C. C. Tecnologia social, autogestão e economia solidária. Rio de Janeiro: Editora FASE, 2009. 